Napredno iskanje

domov www.zdravgozd.si

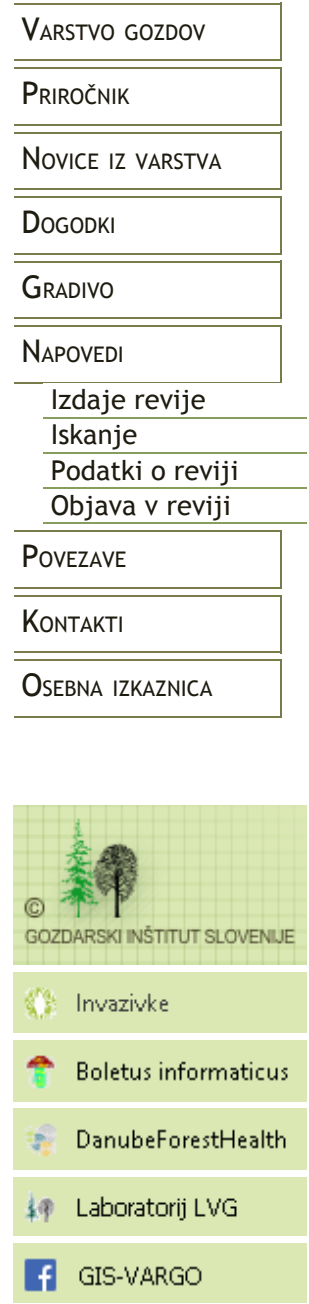

Varstvo gozdov / Napovedi o zdravju gozdov / Napoved

Kratki znanstveni prispevek

Napovedi o zdravju gozdov, 2018

DOI: $10.20315 /$ NZG.42

\title{
Dnevna napoved meteorološke požarne ogroženosti gozdov v Sloveniji z modelom FWI-INCA
} \section{Nikica OGRIS*}

Gozdarski inštitut Slovenije, Večna pot 2, 1000 Ljubljana

*nikica.ogris@gozdis.si

Datum izdaje: 21.08.2018

Veljavnost: 2018

Ključne besede: požarna ogroženost, model, napoved, prognoza, požar, CFFWIS, FWI, INCA, ALADIN, meteorološki indeks požarne ogroženosti gozdov

\section{Povzetek}

Razvili smo sistem za avtomatski izračun dnevne napovedi požarne ogroženosti gozdov z uporabo kanadskega meteorološkega indeksa požarne ogroženosti (FWI), kjer smo za vhodne podatke uporabili meteorološke podatke iz sistema za zelo kratkoročno avtomatizirano napoved INCA/SI s prostorsko ločljivostjo $1 \mathrm{~km} \times 1 \mathrm{~km}$. Del sistema je spletna aplikacija za pregled dnevnih napovedi požarne ogroženost gozdov v Sloveniji izračunane z modelom FWIINCA. Model smo validirali in njegovo točnost primerjali z modelom FWI-ALADIN. Ugotovili smo, da model FWI-INCA na račun boljše prostorske ločljivosti nekoliko bolje napoveduje požarno ogroženost in posledično nastanek požara v naravi. Model FWI-INCA bo lahko v prihodnosti vključen kot podmodel za kratkoročno napoved širjenja gozdnega požara.

\section{Uvod}

Dnevno požarno ogroženost gozdov se izračunava z različnimi metodami. V Evropi je razširjena in uveljavljena uporaba kanadskega meteorološkega indeksa požarne ogroženosti (CFFWIS), npr. uporabljajo ga na Portugalski, Kreti, Italiji, Hrvaškem primorju (Šturm, 2013). Uporablja ga tudi Evropski informacijski sistem za gozdne požare (EFFIS), ki je nastal pod okriljem Evropske komisije (EC, 2018). V Sloveniji smo model CFFWIS implementirali v letu 2014, ko smo za vhodne podatke uporabili podatke numeričnega meteorološkega modela ALADIN/SI, ki ima prostorsko ločljivost 4,4 × 4,4 km in velikost modelske celice 19,4 km² (Ogris in Šturm, 2014; Ogris in sod., 2016). Prostorsko ločljivost napovedi požarne ogroženosti gozdov bi lahko izboljšali z meteorološkimi podatki iz sistema za zelo kratkoročno avtomatizirano napoved INCA/SI s prostorsko ločljivostjo $1 \mathrm{~km} \times 1 \mathrm{~km}$ in napovedjo meteoroloških spremenljivk za $12 \mathrm{ur}$ v naprej (Haiden in sod., 2011; Šajn Slak in sod., 2012).

Cilj raziskave je bil razviti sistem za avtomatski izračun dnevne napovedi meteorološke požarne ogroženosti gozdov za območje Slovenije z uporabo CFFWIS in podatkov iz sistema INCA/SI ter preveriti njegovo točnost.

\section{Metode dela}

Za izračun dnevne napovedi požarne ogroženosti gozdov smo uporabili kanadski meteorološki indeks požarne ogroženosti (CFFWIS). Številčno oceno verjetnosti nastanka gozdnega požara dobimo s pomočjo šestih standardnih komponent indeksa meteorološke požarne ogroženosti gozdov (slika 1). Osnova so tri šifre vlažnosti goriva (šifra vlažnosti drobnega goriva, angl. Fine Fuel Moisture Code - FFMC, šifra vlažnosti srednjega goriva, angl. Duff Moisture Code - DMC, šifra vlažnosti grobega goriva, angl. Drought Code - DC), ki se odzivajo na dnevne spremembe vsebnosti vlage $v$ treh razredih gozdnega goriva z različnimi stopnjami hitrosti sušenja. Vmesna indeksa predstavljata stopnjo širjenja (indeks začetnega širjenja, angl. Initial Spread Index ISI) in količino razpoložljivega goriva (indeks celotnega goriva, angl. Build-Up Index - BUI). Končni indeks širjenja požara je indeks FWI (indeks požarne ogroženosti gozdov, angl. Fire Weather Index - FWI), ki združuje vmesna dva vmesna indeksa in predstavlja intenzivnost 
širjenja požara (slika 1). Uporablja se tudi kot splošni indeks požarne ogroženosti (Lawson in Armitage, 2008). Vse tri šifre vlažnosti goriva (FFMC, DMC in DC) nastopajo v modelu CFFWIS z vrednostmi prejšnjega dne. Izračunano vrednost FWI za končnega uporabnika prikazujemo v petih stopnjah požarne ogroženosti (Uredba o varstvu pred požarom v naravnem okolju, 2014), katerih razrede je izračunal Šturm (2013).

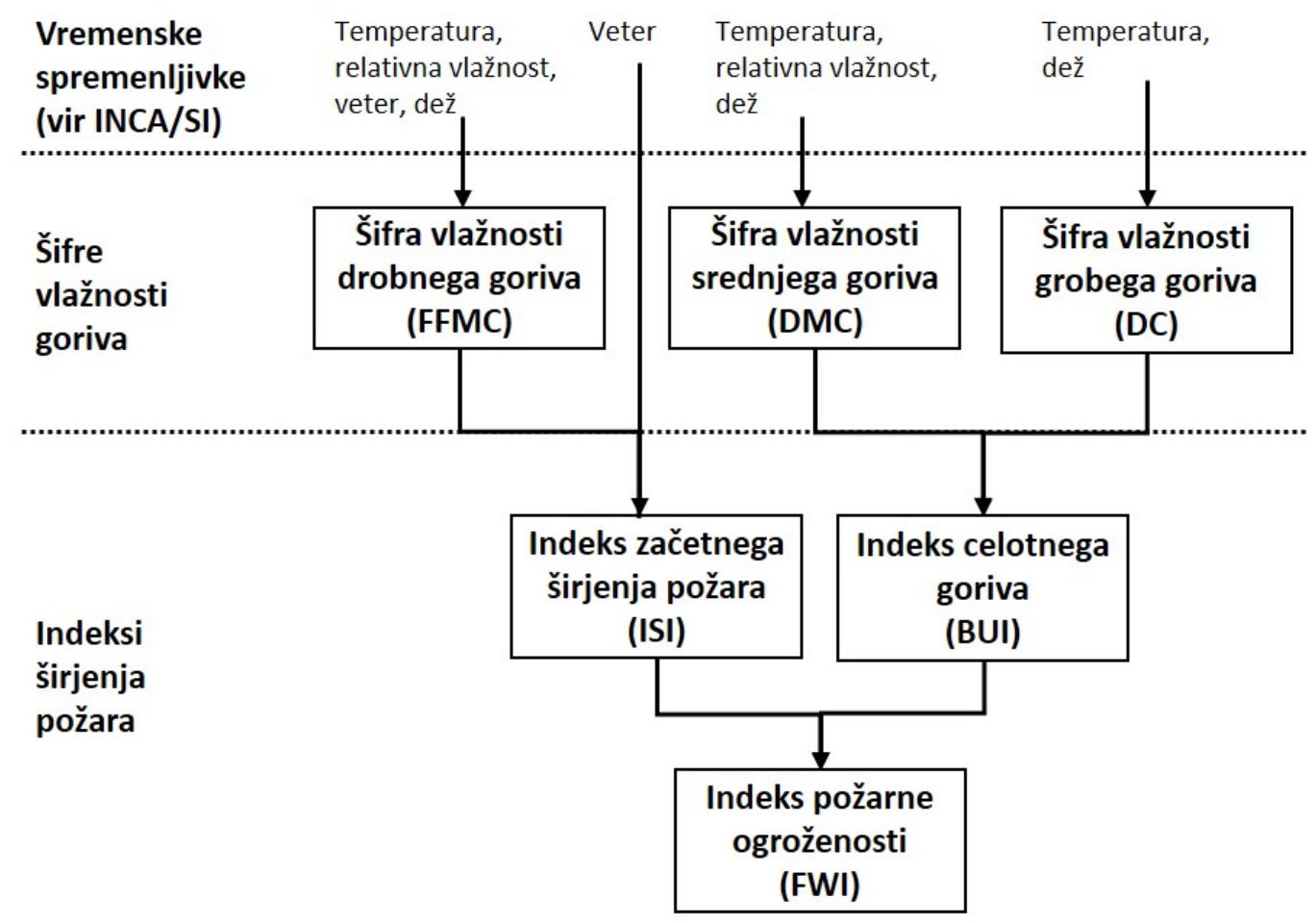

Slika 1: Shema modela FWI

Vhodni podatki za izračun CFFWIS so temperatura zraka $\left({ }^{\circ} \mathrm{C}\right)$, relativna zračna vlažnost $(\%)$,

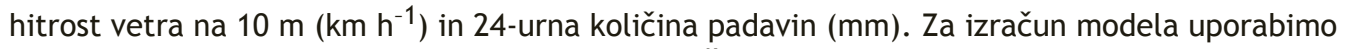
vrednosti vseh omenjenih spremenljivk, ki so izračunane za 12. uro. Te podatke dobimo iz napovedi modela INCA/SI. Večino podatkov iz modela INCA/SI se osveži vsako uro, le podatki o padavinah se osvežijo vsake pol ure. Temu primerno smo prilagodili tudi izračun modela CFFWIS, ki se samodejno izračuna in posodablja od 3. ure zjutraj do 13. ure. Bližje smo 12. uri, zanesljivejše so napovedi. Meteorološki podatki so v GRIB raster formatu (angl. GRIdded Binary), ki vsebuje 13 slojev, kjer prvi sloj predstavlja aktualne (merjenje) podatke, naslednjih 12 slojev pa izračunane napovedi za naslednjih 12 ur. Za izračun CFFWIS smo uporabili originalne formule in postopke izračuna avtorjev (Van Wagner in Pickett, 1985; Van Wagner, 1987), ki so identične formulam, ki smo jih uporabili pri implementaciji modela FWI-ALADIN (Ogris in Šturm, 2014). Kljub temu med modeloma FWI-INCA in FWI-ALADIN obstaja razlika. Model FWI-ALADIN je vektorski in ves izračun poteka na SQL strežniku na nivoju posamezne modelske celice. Model FWI-INCA je v celoti rasterski, zato smo funkcijo in postopek izračuna FWI-INCA razvili od začetka. Funkcijo za izračun FWI-INCA smo napisali v statističnem programu R (R Core Team, 2016) z uporabo knjižnice raster (Hijmans, 2016) in knjižnice R.utils (Bengtsson, 2016). Rezultati izračuna modela FWI-INCA se shranjujejo $v$ rasterski katalog $v$ prostorsko podatkovno zbirko v formatu Microsoft SQL Server 2016.

Spletno aplikacijo za pregled dnevnih napovedi meteorološke požarne ogroženosti gozdov iz modela FWI-INCA smo napisali v programski opremi Microsoft Visual Studio 2017, kjer smo uporabili programski okvir Microsoft .NET Framework 4.6.2 in knjižnico ESRI ArcGIS API for JavaScript 3.16. Spletna aplikacija je objavljena na spletnem strežniku Microsoft Internet Infromation Services 8 v okviru spletnega portala Varstvo gozdov (Ogris, 2012). Spletna interaktivna karta uporablja kartno storitev, ki smo jo objavili na prostorskem strežniku ESRI ArcGIS Server 10.4.1.

Točnost napovedi modela FWI-INCA smo preverjali z zbranimi podatki o gozdnih požarih, ki jih Zavod za gozdove Slovenije beleži v računalniškem programu Varstvo gozdov (Ogris, 2012). Za preverjanje točnosti napovedi modela FWI-INCA smo uporabili z enostavno klasifikacijo frekvence pojavljanja gozdnih požarov po različnih stopnjah požarne ogroženosti FWI. Prav tako smo naredili primerjavo med modeloma FWI-INCA in FWI-ALADIN.

Rezultati 


\section{Spletna aplikacija}

V spletni aplikaciji nastavimo prikaz karte z dvema parametroma: leto in datum (slika 2) (Ogris, 2018). Prvi parameter je v obliki spustnega seznama, drugi pa v obliki drsnega traku. Z izbiro leta določimo obdobje, za katero želimo pregledovati karte napovedi meteorološke požarne ogroženosti gozdov. V aplikaciji je na voljo samo pregled izračuna FWI-INCA. Na interaktivni spletni karti, ki je opisana $v$ nadaljevanju, je na voljo razširjen nabor grafičnih slojev vključno z vsemi šestimi komponentami CFFWIS. Z drsnim trakom nastavimo dan v izbranem letu, za katerega želimo prikazati napoved FWI (s klikom na levi miškin gumb in vlek $\checkmark$ levo ali desno stran, lahko pa si pomagamo s smernimi tipkami na tipkovnici). Pod drsnim trakom so na voljo kontrolni gumbi, s katerimi se lahko premikamo za en dan naprej ali nazaj, na začetek (1. januar) ali na konec (31. december) drsnega traku ter gumba za zagon in zaustavitev samodejne animacije.

\section{Dnevna napoved požarne ogroženosti gozdov z modelom FWI-INCA - spletna aplikacija}

\section{Nikica OGRIS}

Gozdarski inštitut Slovenije, Večna pot 2, 1000 Ljubljana

*nikica.ogris@gozdis.si

Datum izdaje: 11.08.2018

Veljavnost: 11.08 .2018

Ključne besede: požarna ogroženost, model, napoved, prognoza, požar, FWI, INCA, meteorološki indeks požarne ogroženosti gozdov

\section{Karta požarne ogroženosti gozdov}

Leto: $2018 \vee$
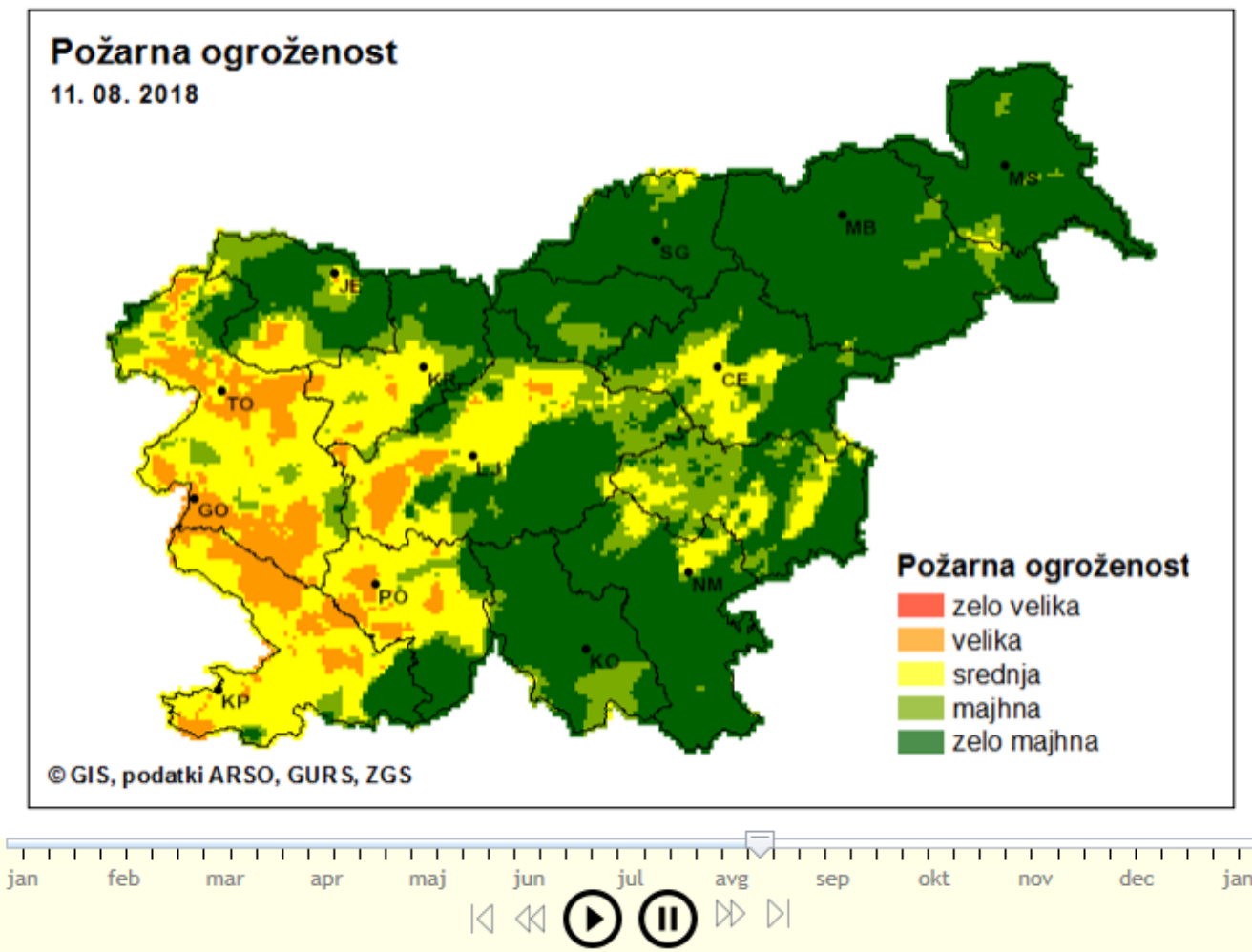

\section{Interaktivna karta}

Analiza požarne ogroženosti gozdov na interaktivni karti.

Slika 2: Spletna aplikacija za prikaz napovedi požarne ogroženosti gozdov z modelom FWI-INCA (http://www.zdravgozd.si/prognoze zapis.aspx?idpor=41) 
$\mathrm{Na}$ interaktivni spletni karti imamo na voljo več orodij in možnosti za analizo kot pri osnovni spletni aplikaciji (Ogris, 2018). Za osnovno orientacijo v prostoru lahko izbiramo med tremi grafičnimi podlagami (slika 3): topografska karta (GURS), digitalni ortofoto (GURS) in meje gozdnogospodarskih območij (GGO) Zavoda za gozdove Slovenije. Model FWI-INCA ima naslednje možne grafične sloje: požarna ogroženost ( $v$ petih razredih), indeks požarne ogroženosti gozdov (FWI), indeks celotnega goriva (BUI), indeks začetnega širjenja (ISI), šifra vlažnosti grobega goriva (DC), šifra vlažnosti srednjega goriva (DMC), šifra vlažnosti drobnega goriva (FFMC). Vse navedene grafične sloje lahko poljubno vklapljamo ali izklapljamo.

$\mathrm{Na}$ vrhu spletnega obrazca interaktivne karte imamo na voljo naslednje kontrolnike (slika 3): (1) drsni trak, s katerim izberemo dan napovedi; (2) v napisu Trenutno se izpiše izbrani dan; (3) set standardnih kontrolnikov za delo s karto, kot so približaj, oddalji, premakni, tiskanje, iskanje, seznam grafičnih slojev, merjenje razdalj in površin ter pregledna karta. Legenda barv je $v$ interaktivni karti enaka kot v spletni aplikaciji za hiter pregled nad območjem cele Slovenije in je prikazana $v$ kazalu grafičnih slojev.

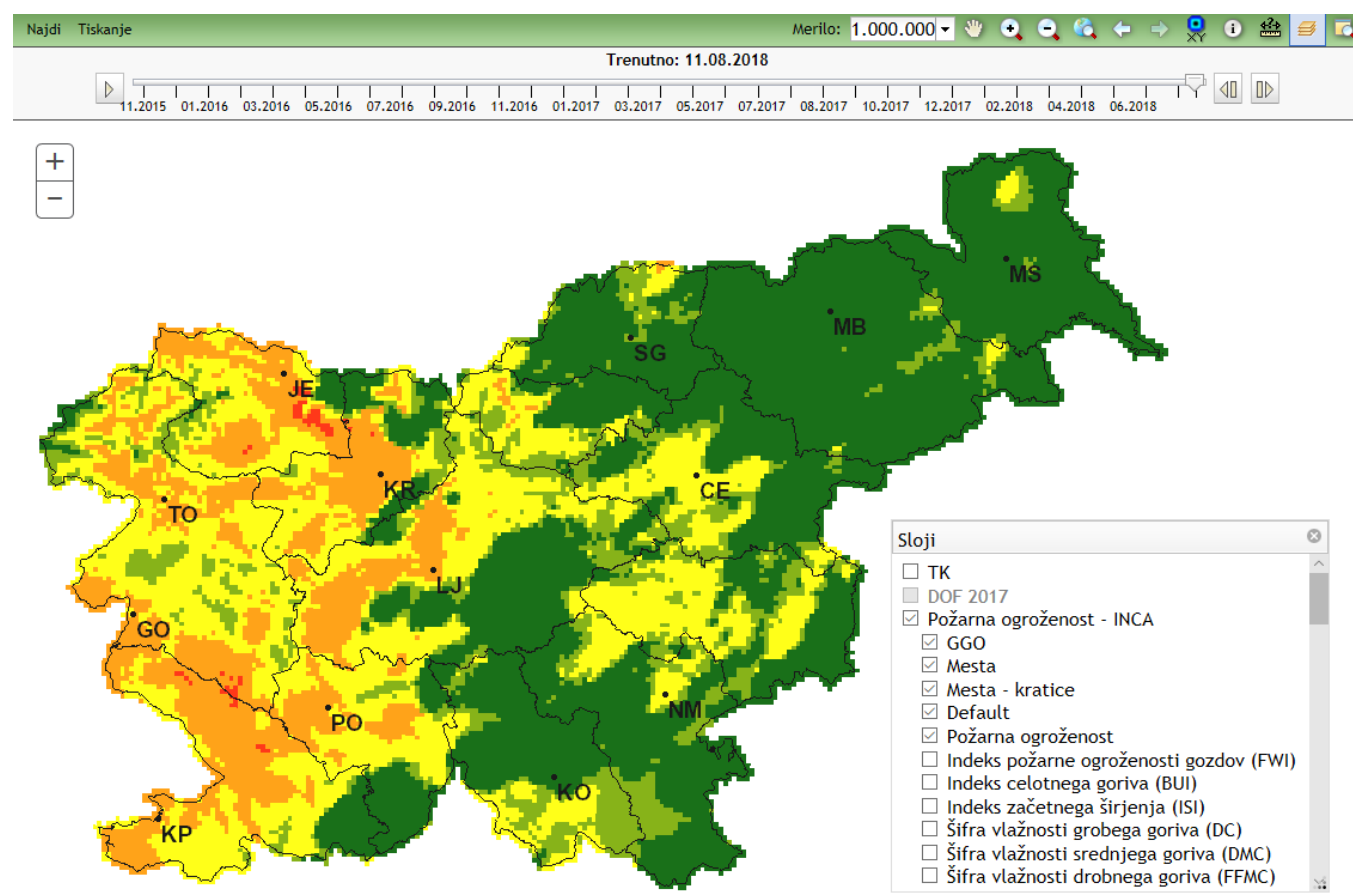

@Gozdarski inštitut Slovenije | Podatki GURS, GIS, ZGS, ARSO

Slika 3: Interaktivna spletna karta za pregled in analizo šestih komponent meteorološkega indeksa požarne ogroženosti gozdov FWI-INCA (http: / / www.zdravgozd.si/karta.aspx?idpor=663bd534-319c-49e0-887805487b3cd637)

\section{Validacija modela FWI}

Za validacijo modelov FWI-INCA in FWI-ALADIN smo vključili vse gozdne požare, ki so nastali od 10. 11. 2015 do 10. 8. 2018 in so bili zbrani v računalniškemu programu Varstvo gozdov do 10. 8. 2018. Takšnih požarov je bilo skupaj 224. Pri treh požarih je manjkala napoved modela FWIALADIN, zato smo jih izključili iz analize. V končno validacijo je bilo vključenih 221 požarov.

Povprečna površina gozdnega požara v obravnavanem obdobju je bila 4,51 ha, največja pa 459,43 ha. V posameznem gozdnem požaru je bilo povprečno poškodovanih $13,9 \mathrm{~m}^{3}$ iglavcev in $16,6 \mathrm{~m}^{3}$ listavcev. Povprečni delež po tipu gozdnega požara podtalni, talni, vršni, je bil 2,1 \%, $93,4 \%, 4,6 \%$. Povprečne vremenske razmere so bile: suho $(93,7 \%)$, mirno ozračje $(50,7 \%)$ in sončno $(69,7 \%)$. Samo dobra polovica gozdnih požarov je imela znani vzrok nastanka (preglednica 1). Naravni vzroki (npr. strela) so bili zabeleženi samo pri 5,0 \% požarov. Človekova aktivnost je bila vzrok za več kot polovico nastanka gozdnih požarov predvsem zaradi nepazljivosti, kot so dela pri kmetijskih opravilih, na komunikacijah (npr. železnice, ceste) in gozdarskih opravilih.

Preglednica 1: Vzroki gozdnih požarov v obdobju od 10. 11. 2015 do 10. 8. $2018(\mathrm{~N}=221)$

\begin{tabular}{llr} 
Kategorija & Vzrok & Delež požarov \\
\hline 1 & znani vzroki & 55,2 \\
1.1 & človek & 50,2
\end{tabular}


Za izbrane gozdne požare je bil 95 \% interval zaupanja FWI-INCA 11,3 +/- 1,3, FWI-ALADIN pa je bil nižji, tj. 8,5 +/- 0,9 (slika 4). S t-testom smo preskusili, ali sta srednji vrednosti FWI-INCA in FWI-ALADIN enaki in ugotovili smo, da sta statistično različni $(p<0,001)$. Analiza po stopnjah požarne ogroženosti je pokazala, da sta oba načina izračuna CFFWIS imela več kot polovico primerov gozdnih požarov razporejenih v zelo majhni in majhni stopnji požarne ogroženosti. Izračun FWI-ALADIN jih je imel za 10,9 \% več kot izračun FWI-INCA (preglednica 2). Izračun FWI-INCA je imel posledično tudi večji delež gozdnih požarov v višjih stopnjah požarne ogroženosti.

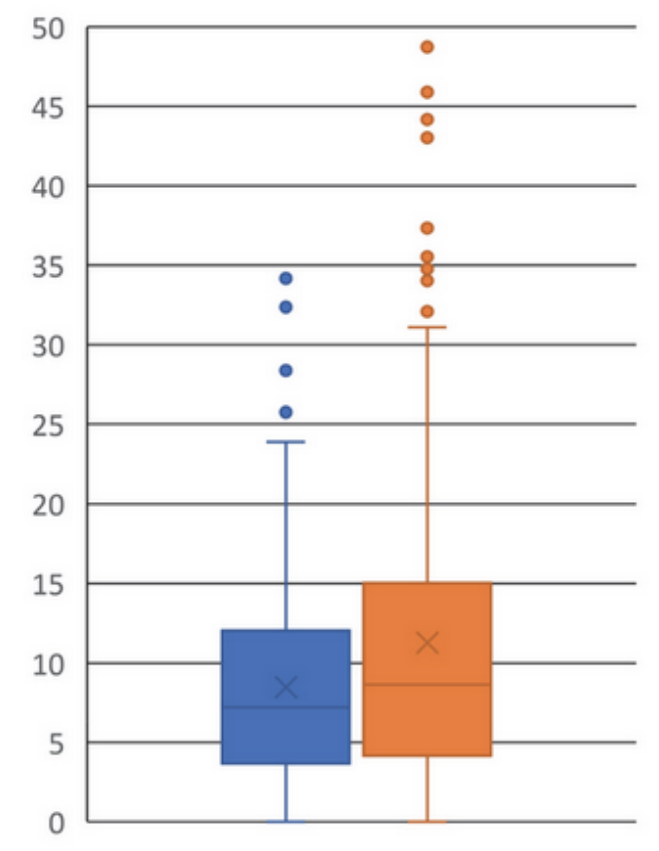

FWI-ALADIN $\square$ FWI-INCA

Slika 4: Okvir z ročaji za izračunane vrednosti FWI-INCA in FWI-ALADIN za območje gozdnih požarov v obdobju od 10. 11.2015 do 10. 8. 2018

Preglednica 2: Razporeditev gozdnih požarov po stopnjah požarne ogroženosti modela FWI-INCA in FWI-ALADIN v obdobju od 10. 11. 2015 do 10. 8. $2018(\%, N=221)$

Požarna ogroženost

zelo majhna

majhna

srednja

velika

zelo velika
FWI-INCA

23, 1

29,0

28,5

14,5

5,0
FWI-ALADIN 30,8

32,1

25,8

10,9

0,5

\section{Diskusija}

Srednja vrednost FWI-INCA je bila značilno višja kot pri FWI-ALADIN, prav tako je bilo večje število gozdnih požarov razvrščenih $v$ višje stopnje požarne ogroženosti pri FWI-INCA. Zato lahko trdimo, da je napoved FWI-INCA nekoliko bolj točna kot napoved FWI-ALADIN, saj je večja verjetnost nastanka gozdnega požara pri višjih vrednostih FWI (Dimitrakopoulos in sod., 2011). 
Prednost pri uporabi podatkov INCA/SI je povečanje prostorske ločljivosti napovedi, ki pa je omejena zgolj za tekoči dan. Tako za napoved požarne ogroženosti gozdov za dva in tri dni vnaprej še vedno uporabljamo rezultate modela FWI-ALADIN.

Več kot polovico vseh gozdnih požarov je povzročil človek pri nižjih vrednostih požarne ogroženosti FWI. Kljub temu so Carvalho in sod. (2008) potrdili, da FWI skupaj z relativno zračno vlažnostjo in šifro grobega goriva pojasni kar 80,2 \% variabilnosti povprečne mesečne površine požarov na Portugalskem. Primerjalna študija uporabe petih metod ocenjevanja požarne ogroženosti v šestih regijah v Franciji, Italiji in na Portugalskem, je pokazala, da je pri napovedovanju števila in površine požarov najbolj učinkovit prav CFFWIS (Viegas in sod., 2000). Podobna študija manjka za območje Slovenije, kjer bi primerjali med seboj obstoječe modele požarne ogroženosti v Sloveniji. V primerjavo bi bilo smiselno vključiti metodo, ki so jo razvili Kobler in sod. (2006) in temelji na metodi strojnega učenja ter je implementirana v sistem GISUJME na Upravi RS za zaščito in reševanje. Poleg te bi bilo treba vključiti tudi izpopolnjeno vzhodnonemško metodo, ki jo uporablja ARSO za določanje stopenj požarne ogroženosti (Pečenko, 1994).

Višja prostorska ločljivost modela FWI-INCA bo nujna pri nadgradnji sistema s kratkoročno napovedjo širjenja požarov (Van Wagner in sod., 1992), pri katerem bodo kratkoročne napovedi iz sistema INCA (predvsem vetra $v$ visoki krajevni ločljivosti) neobhodne. Za razvoj modela za kratkoročno napoved širjenja požarov je potrebna kakovostna karta tipov goriv, ki za Slovenijo še ni izdelana (Šturm, 2013). Model za kratkoročno napoved širjenja požarov bi bil zelo uporabno orodje gasilcem pri načrtovanju gašenja požarov.

\section{Zahvala}

Raziskava je nastala v okviru Javne gozdarske službe na Gozdarskem inštitutu Slovenije, naloge 2A Usmerjanje in strokovno vodenje poročevalske, prognostične-diagnostične službe za gozdove (PPD), ki jo financira Ministrstvo za kmetijstvo, gozdarstvo in prehrano iz proračuna Republike Slovenije. Zahvaljujemo se Zavodu za gozdove Slovenije za podatke o gozdnih požarih, s katerimi smo validirali model CFFWIS. Agenciji RS za okolje še posebej Nevi Pristov za podatke iz sistema INCA/SI. Končna zahvala gre recenzentu dr. Tomažu Šturmu, ki je bistveno prispeval k izboljšanju prispevka.

Viri

Bengtsson H. 2016. R.utils: Various Programming Utilities. R package version 2.5.0. https: / / CRAN.R-project.org/package=R.utils

Carvalho A., Flannigan M.D., Logan K., Miranda A.I., Borrego C. 2008. Fire activity in Portugal and its relationship to weather and the Canadian Fire Weather Index System. International Journal of Wildland Fire 17, 3: 328-338

Dimitrakopoulos A.P., Bemmerzouk A.M., Mitsopoulos I.D. 2011. Evaluation of the Canadian fire weather index system in an eastern Mediterranean environment. Meteorological Applications, 18, 1: 83-93. Povezava: https://rmets.onlinelibrary.wiley.com/doi/abs/10.1002/met.214

EC. 2018. European Forest Fire Information System (EFFIS). European Commission (EC), Joint Research Centre (JRC). http: / / effis.jrc.ec.europa.eu (10. 8. 2018)

Haiden T., Kann A., Wittmann C., Pistotnik G., Bica B., Gruber C. 2011. The Integrated Nowcasting through Comprehensive Analysis (INCA) System and Its Validation over the Eastern Alpine Region. Weather and Forecasting, 26, 2: 166-183. Povezava: http://dx.doi.org/10.1175/2010WAF2222451.1

Hijmans R.J. 2016. raster: Geographic Data Analysis and Modeling. R package version 2.5-8. https: / /CRAN.R-project.org /package=raster.

Kobler A., Ogrinc P., Skok I., Fajfar D., Džeroski S. 2006. Končno poročilo o rezultatih raziskovalnega projekta "Napovedovalni GIS model požarne ogroženosti naravnega okolja". Raziskovalni projekt št. M1-0032 v okviru Ciljnega raziskovalnega programa "Znanje za varnost in mir 2004-2010", pogodba št. 3311-04-828032. Inštitut Jožef Stefan, Gozdarski inštitut Slovenije, IGEA d.o.o.: 53 str.

Lawson B.D., Armitage O.B. 2008. Weather Guide for the Canadian Forest Fire Danger Rating System. Edmonton, Alberta, Canadian Forest Service Northern Forestry Centre: 73 str.

Ogris N. 2012. Prognostične osnove za varstvo gozdov Slovenije. Ljubljana, Silva Slovenica: 104 str.

Ogris N. 2018. Dnevna napoved požarne ogroženosti gozdov z modelom FWI-INCA - spletna aplikacija. Napovedi o zdravju gozdov, 2018. Povezava: http://www.zdravgozd.si/prognoze zapis.aspx?idpor=41

Ogris N., Pristov N., Šturm T. 2016. Izboljšave modela za dnevno napoved verjetnosti nastanka gozdnega požara v letu 2015. Novice iz varstva gozdov, 9: 1-2

Ogris N., Šturm T. 2014. Meteorološki indeks požarne ogroženosti gozdov. Napovedi o zdravju gozdov, 2014. Povezava: http://www.zdravgozd.si/prognoze zapis.aspx?idpor=6

Pečenko A. 1994. Določanje stopenj ogroženosti naravnega okolja v Sloveniji. Ujma, 8 193-196 
R Core Team. 2016. R: A language and environment for statistical computing. R Foundation for Statistical Computing, Vienna, Austria. URL: https://www.R-project.org.

Šajn Slak A., Kršmanc R., Merše J. 2012. INCA-CE - projekt, ki povezuje meteorološke službe osrednje Evrope s končnimi uporabniki. Vetrnica, 4: 61-63

Šturm T. 2013. Uporaba tehnologije GIS za napovedovanje pojavljanja gozdnih požarov v Sloveniji. Ljubljana, T. Šturm, Univerza v Ljubljani, Fakulteta za gradbeništvo in geodezijo: 138 str.

Uredba o varstvu pred požarom v naravnem okolju. Uradni list RS, št. 20/14

Van Wagner C.E. 1987. Development and structure of the canadian forest fire weather index system. Forestry Technical Report, 35: 37

Van Wagner C.E., Pickett T.L. 1985. Equations and FORTRAN program for the canadian forest fire weather index system. Forestry Technical Report, 33: 18

Van Wagner C.E., Stocks B.J., Lawson B.D., Alexander M.E., Lynham T.J., McAlpine R.S. 1992. Development and structure of the canadian forest fire behavior prediction system. Information report, ST-X-3: 1-63

Viegas D.X., Bovio G., Ferreira A., Nosenzo A., Sol B. 2000. Comparative study of various methods of fire danger evaluation in southern Europe. International Journal of Wildland Fire, 9, 4: 235-246. Povezava: https://www.publish.csiro.au/paper/WF00015

Citiranje: Nikica OGRIS. 2018. Dnevna napoved meteorološke požarne ogroženosti gozdov v Sloveniji z modelom FWI-INCA. Napovedi o zdravju gozdov, 2018. URL: https:// www.zdravgozd.si/prognoze_zapis.aspx?idpor=42. DOI: $10.20315 /$ NZG. 42

Prispelo: 16. 08. 2018. Sprejeto: 21. 08. 2018. Objavljeno: 21. 08. 2018.

na vrh strani 